\title{
GEROBAK "MANTAP" UNTUK SERVICE-LEARNING UKM KAMPUNG UNGGULAN KUE
}

\author{
Claudia Filiana Sunaryo ${ }^{1 *}$, Meinasari Ardelia Tedja ${ }^{1}$, Jenniffer Magdalena $^{1}$, \\ Madeleine Christie Liady ${ }^{1}$, Grace Mulyono ${ }^{1}$ \\ ${ }^{1}$ Program Studi Desain Interior, Fakultas Seni dan Desain, Universitas Kristen Petra \\ Jl. Siwalankerto 121-131, Surabaya 60236 \\ *Penulis korespondensi; Email: claudiafiliana@gmail.com
}

\begin{abstract}
Abstrak: UKM atau Usaha Kecil Menengah merupakan salah satu metode usaha yang banyak berkontribusi secara positif terhadap perekonomian negara. UKM Kampung Unggulan Kue merupakan salah satu UKM di Surabaya yang memiliki potensi unggulan menghasilkan produk kue basah. Kampung Unggulan Kue saat ini memiliki permasalahan keterbatasan perabot yang mendukung penjualan. Untuk menjawab permasalahan tersebut, mahasiswa melakukan perkuliahan dengan metode Service-Learning dimana pemecahan masalah tersebut akan melibatkan mahasiswa secara langsung untuk mengembangkan keterampilan akademik, rasa tanggung jawab, dan komitmen mahasiswa terhadap masyarakat. Metode penelitian yang digunakan adalah metode deskripsi kualitatif analisis digunakan untuk mengidentifikasi keadaan langsung di lapangan, literatur dan perancangan. Setelah melewati proses diskusidan analisis UKM, penelitian ini menghasilkan sebuah "gerobak" yang bisa dipasang dan dibongkar dengan mudah yang digunakan untuk berjualan di bazar, car free day, maupun pasar malam.
\end{abstract}

Kata kunci: UKM; service-learning; kampung unggulan kue.

\begin{abstract}
UKM or Small to Medium Enterprise is one of the ways that have great and positive contribution to the country's economy. This Enterprise, Kampung Unggulan Kue is one of the Enterprise in Surabaya which has the potential to produce dessert products. Currently Kampung Unggulan Kue has the problem of limited furniture that supports their sales. To answer these problems, students conduct lectures with the Service-Learning method where information will be needed for students who are developing academic abilities, a sense of responsibility, and student's commitment to society. The research method used are descriptive analysis method for direct research, literature and design. After going through the discussion and analysis process from the Enterprise, this research produced a "cart" that could be easily lifted and dismantled to sell at bazaars, car free day and night markets.
\end{abstract}

Keywords: Small to medium enterprise; service learning; kampung unggulan kue.

\section{PENDAHULUAN}

UKM atau yang biasa disebut dengan Usaha Kecil Menengah memberikan banyak dampak positif terhadap masyarakat dan negara. Negara mendapatkan kontribusi dalam pengembangan ekonomi menurut Ardiana, dkk. (Ardiana, Brahmayanti, Subaedi, 2010). Selain itu UKM juga telah mendukung 99,45\% dari tenaga kerja di Indonesia untuk periode 2000-2003. Disini bisa terlihat bahwa setiap UKM yang ada di Indonesia memiliki dampak yang cukup besar bagi perekonomian negara dan membantu menurunkan angka pengangguran di Indonesia. Karena adanya keterbatasan biaya, UKM menghadapi permasalahan dalam mengembangkan usahanya.

UKM Kampung Unggulan Kue ini memberikan kesempatan kepada warga sekitar untuk bergabung di dalam UKM ini. Di dalam UKM ini mereka berkembang bersama-sama untuk memajukan usaha tersebut. UKM terletak di Rusun Penjaringan Sari dan tidak memiliki outlet tetap serta lokasi perabot untuk berjualan kue setiap hari. Kue yang dibuat disesuaikan dengan jumlah pesanan yang ada, sehingga pendistribusian kue terbatas. Dengan permasalahan ini, perkembangan UKM Kampung Kue cukup terhambat.

UKM kampung kue perlu mengembangkan usaha dengan berjualan ditempat yang ramai pengunjung seperti bazar, car free day, maupun pasar malam. Promosi penjualan pada bazar, akan membuat mereka semakin dikenal oleh masyarakat luas, khususnya masyarakat Surabaya.

Pelaksanaan Service-Learning ini didasari oleh mata kuliah Desain Produk Interior 3, yaitu mata kuliah program studi desain interior yang melakukan perancangan produk untuk UKM yang ada di Surabaya dengan melibatkan mahasiswa dan ang- 
gota UKM secara langsung dan ada banyak diskusi yang dibutuhkan dalam proses Service-Learning, dimana luaran yang dihasilkan, yaitu berupa produk akan diserahkan kepada UKM. Service-Learning digunakan sebagai metode pembelajaran untuk mahasiswa, dimana mahasiswa dapat belajar secara langsung untuk memahami, menganalisa, dan memberikan solusi terhadap masalah yang ada. Selain itu, mahasiswa dapat belajar untuk mengembangkan diri, bertanggung jawab, dan mengembangkan keterampilan akademik. (Munasyita, 2017)

Metode yang digunakan dalam perancangan Service-Learning terdiri dari melalui emphatize( tahapan pengumpulan data), define (menganalisa permasalahan), ideate (tahapan untuk sketsa ide), prototype (memproduksi desain), test (tahapan dimana melakukan uji coba dan meminta saran dari orang lain), dan menyerahkan produk kepada UKM Kampung Unggulan Kue. Dalam penelitian ini, anggota dari UKM Kampung Kue ini berpartisipasi dalam proses, mulai dari perumusan masalah, konsep dan ide, percobaan dari prototype produk yang dihasilkan.

\section{METODE PELAKSANAAN}

Pelaksanaan Service-Learning ini menggunakan 5 tahapan desain yang melibatkan kurang lebih 20 anggota dari UKM Kampung Kue tersebut dalam keseluruhan prosesnya dari awal hingga akhir. Tahapan tersebut meliputi, empathize, define, ideate, prototype, test. Dalam pelaksanaan Service-Learning ini tidak hanya pihak UKM saja yang terlibat, tetapi desainer juga terlibat dalam kegiatan seharihari UKM, mulai dari proses pembuatan kue, packaging, dan penjualan sebagai bagian dari tahapan emphatize sehingga desainer dapat memahami secara langsung aktivitas yang ada didalam UKM. Dari tahapan define, ideate, prototype, dan test pihak UKM dikunjungi secara berkala untuk mendapatkan masukan mengenai desain gerobak. Setelah tahapan prototype, desainer melakukan test terhadap produk yang akan dihasilkan sebagai produk yang bisa digunakan dengan baik, tidak hanya secara fungsional tetapi juga secara estetis.

\section{HASIL DAN PEMBAHASAN}

Dalam proses Service-Learning ini, dilakukan diskusi secara berkelanjutan dari awal hingga penyerahan gerobak untuk UKM. Diskusi dilakukan selama kurang lebih 3 kali dari tahapan emphatize (pendataan), define (pendataan dengan lebih detail lagi), ideate (diskusi konsep dan kritik dari desain yang ada). Setelah itu pihak UKM dilibatkan kembali dalam tahapan test (berjualan dengan menggunakan gerobak tersebut) untuk memberikan evaluasi terhadap gerobak.

\section{Empathize}

Service-Learning ini dimulai dengan melakukan diskusi pada UKM Kampung Unggulan Kue yang terletak di Rusun Penjaringan Sari FB-212, Kel. Penjaringansari, Kec. Rungkut, Surabaya. Pada diskusi yang pertama, dilakukan pengumpulan data mengenai permasalahan yang ada pada UKM, dari sistem UKM hingga penjualan kue, aktivitas yang dilakukan, anggota UKM. UKM menceritakan secara keseluruhan mengenai setiap aktivitas yang ada pada UKM. UKM Kampung Unggulan Kue memproduksi kue-kue tradisional Indonesia. Makanan tradisional adalah makanan, minuman, makanan jajanan serta bahan campuran yang digunakan secara tradisional dan telah lama berkembang secara spesifik di daerah atau masyarakat Indonesia. Kue tradisional dibuat dengan varian yang cukup banyak, mulai dari kue lumpur, lemper, pastel, klepon, wajik, hingga nagasari. Cara pembuatan kue tersebut sangat bermacam-macam, mulai dari dikukus, digoreng, direbus, dan dibakar. (Nurhayati, 2014)

Setiap warga yang tinggal bersama di rusun ini dapat berpartisipasi sebagai anggota UKM. Kue yang diproduki UKM disesuaikan order yang diminta, sehingga jumlah kue yang diproduksi perhari tidak stabil. Tempat yang digunakan untuk memproduksi kue adalah kamar masing-masing dari setiap anggota. Kamar yang ada pada rusun penjaringan sari tidaklah besar, dan digunakan untuk berbagai macam aktivitas sehari-hari. Dengan sistem penjualan yang bergantung dengan pesanan, menjadikan penghasilan dari UKM ini tidaklah stabil.

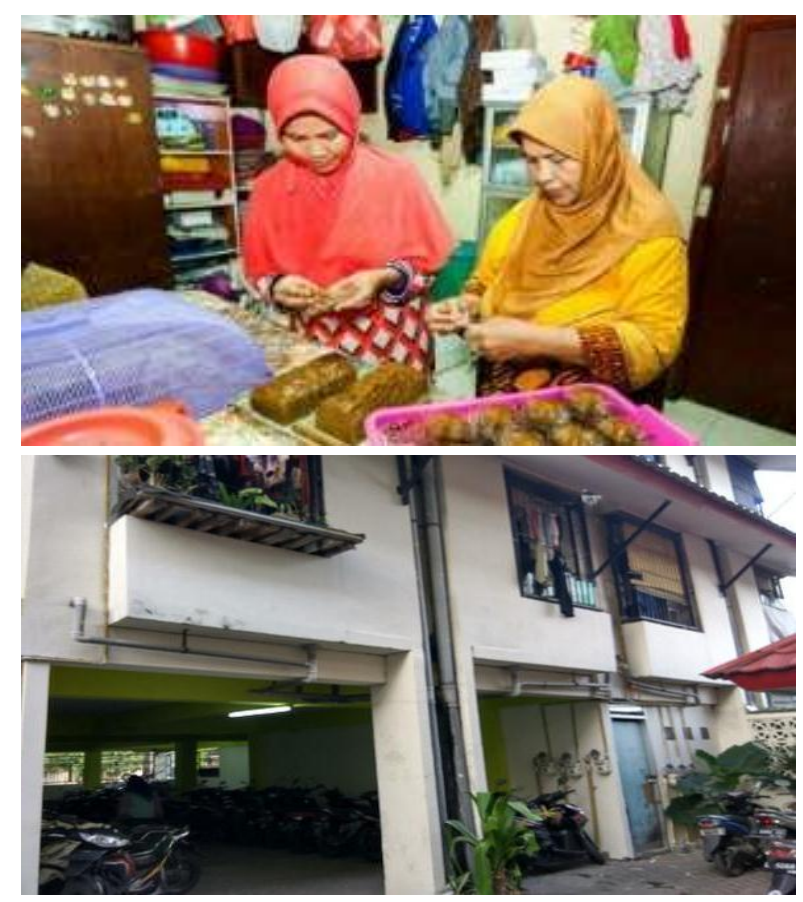

Gambar 1. Rusun Kampung Kue 


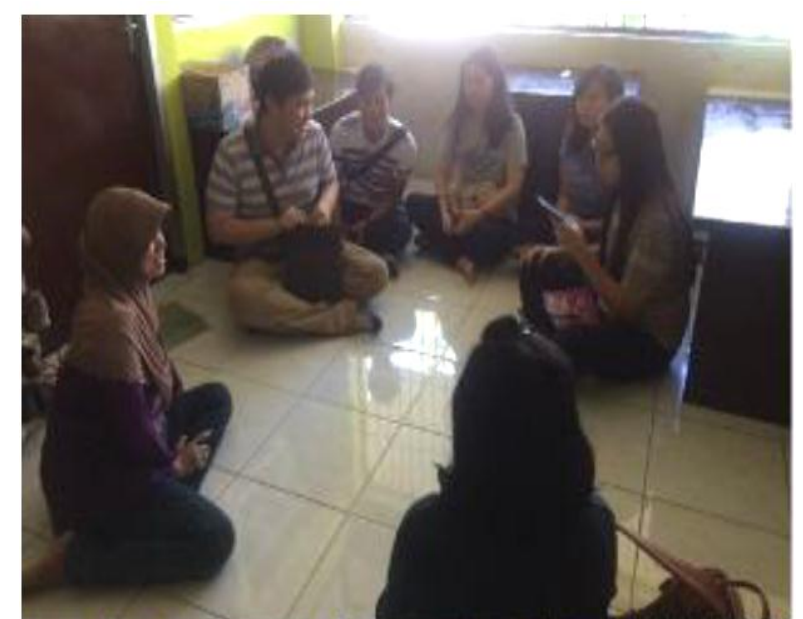

Gambar 2. Proses Diskusi dan Pendataan

\section{Define}

Tahapan selanjutnya adalah analisa, mahasiswa menganalisa setiap masalah dan kebutuhan yang ada. Mahasiswa mempetakan setiap kebutuhan yang ada pada UKM melalui emphaty map.

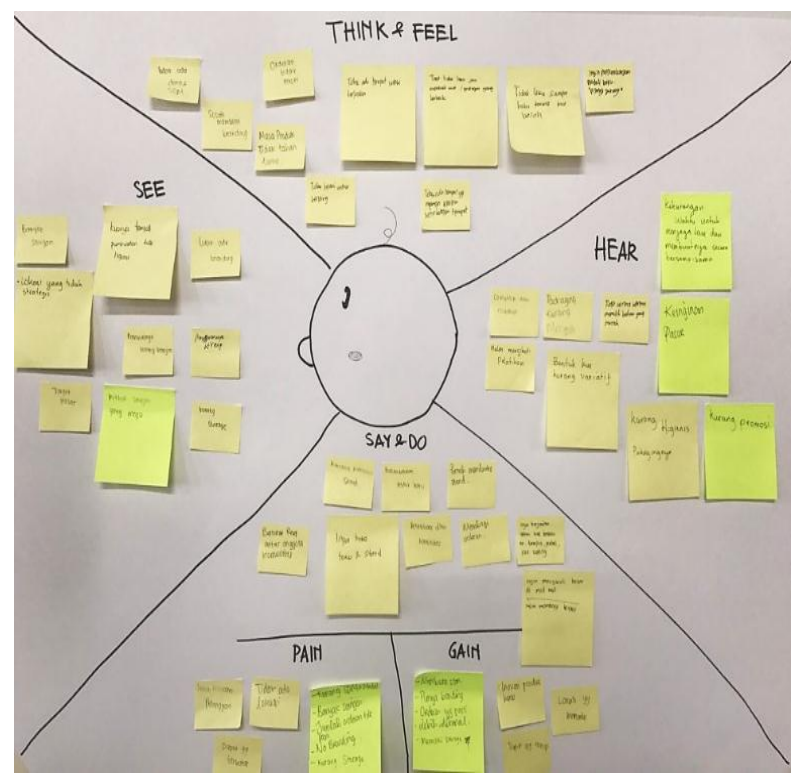

Gambar 3. Emphaty map

Sebelum masuk ketahapan ideate, dilakukan proses diskusi kembali pada UKM untuk melakukan pendataan secara kuantitatif dan lebih detail, dengan melakukan pendataan jumlah kue, jenis kue, dan ukuran dari setiap jenis kue. Jenis packaging yang digunakan juga berpengaruh dalam tahapan ideate yang akan dilakukan. Desainer memberikan kesimpulan bahwa produk yang cocok untuk UKM Kampung Kue adalah produk yang adaptable dan praktis. Perancangan produk yang adaptable bertujuan untuk mewadahi seluruh aktivitas penjualan dan memudahkan para penjual kue agar penjualan dapat berlangsung secara efisien.


Gambar 4. Produksi Kue

\section{Ideate}

Pada tahapan ideate, setiap solusi dari permasalahan yang ada dilanjutkan dengan pembuatan sketsa. Setelah sketsa ide selesai, ServiceLearning dilanjutkan dengan proses diskusi yang ketiga. Pada tahapan ini kami meminta perwakilan dari UKM untuk mengevaluasi desain gerobak yang telah dibuat. Pihak UKM juga memberikan saran terkait dengan kebutuhannya untuk menggunakan gerobak tersebut.

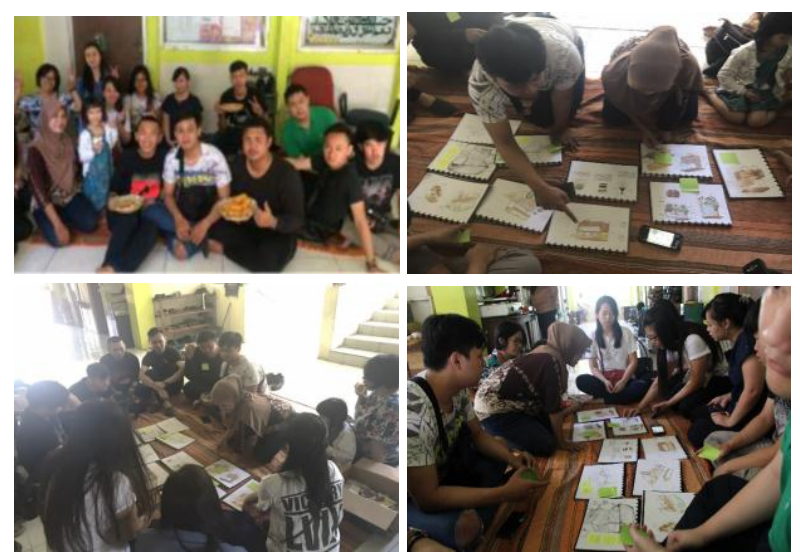

Gambar 5. Evaluasi desain gerobak

Untuk memproduksi kue secara stabil, UKM memerlukan sebuah outlet yang tetap dengan perabot yang digunakan. Solusi dari permasalahan ini adalah dengan mendesain sebuah "gerobak" yang dapat digunakan untuk berjualan di bazaar, car free day, maupun pasar malam. Karena lokasi yang digunakan untuk berjualan tidaklah tetap, sehingga diperlukan sebuah produk yang mudah untuk dipindah-pindahkan oleh satu atau dua orang(user friendly).(Agustin dkk., 2014) 


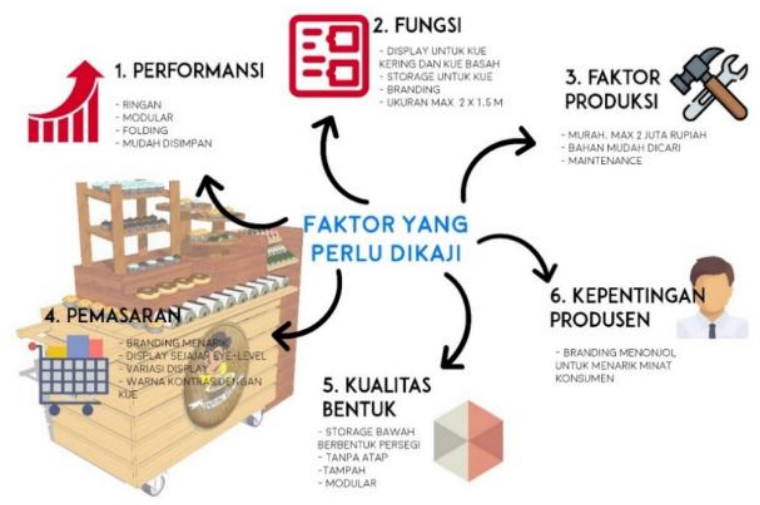

Gambar 6. Faktor yang perlu dikaji untuk produk

\section{Prototype}

Setelah menerima kritik, desain direvisi untuk menghasilkan desain yang maksimal. Desain final disetujui oleh pihak UKM, desain tersebut kemudian diproduksi 1:1. Gerobak diproduksi dengan menggunakan material kayu pallet, bambu, dan tampah yang bisa dibongkar, dipasang, dan beradaptasi dengan mudah.

Semua rak yang ada pada bagian atas dapat dimasukkan pada bagian dalam gerobak. Rak yang menggunakan sistem knock down sehingga memudahkan untuk meringkas dan memasang kembali hanya dengan satu orang saja.

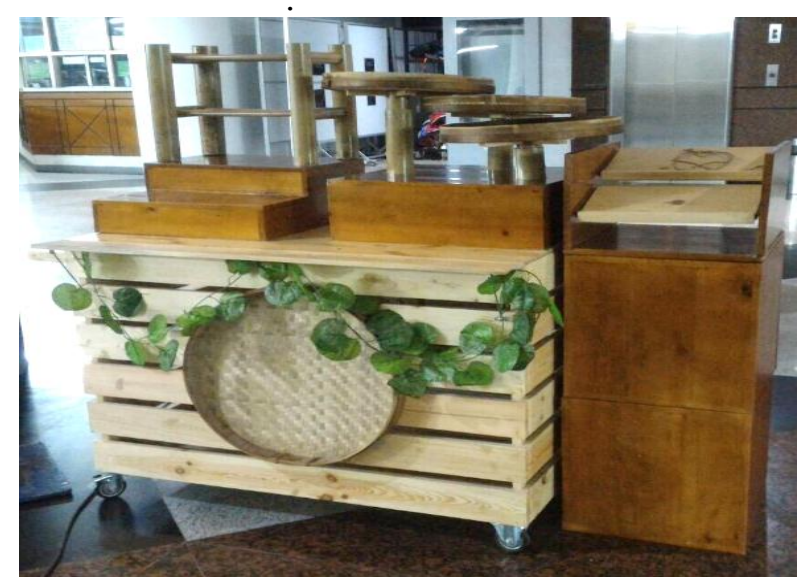

Gambar 7. Gerobak yang siap digunakan

Rak bambu dapat dilepas dan dimasukkan dalam kedua rak yang lain sehingga ruang didalam gerobak dapat dimanfaatkan secara maksimal.
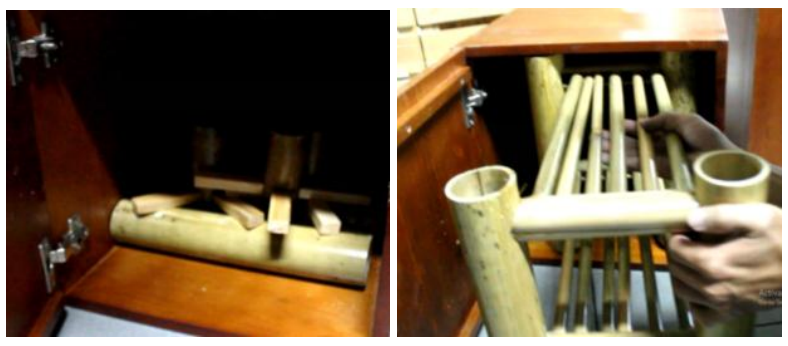

Gambar 8. Penyimpanan rak bambu



Gambar 9. Pengaturan rak di dalam gerobak

Rak dimasukkan semua kedalam gerobak dan gerobak dapat dipindahkan dengan didorong karena menggunakan roda dibagian bawahnya yang cukup mempermudah para anggota UKM.

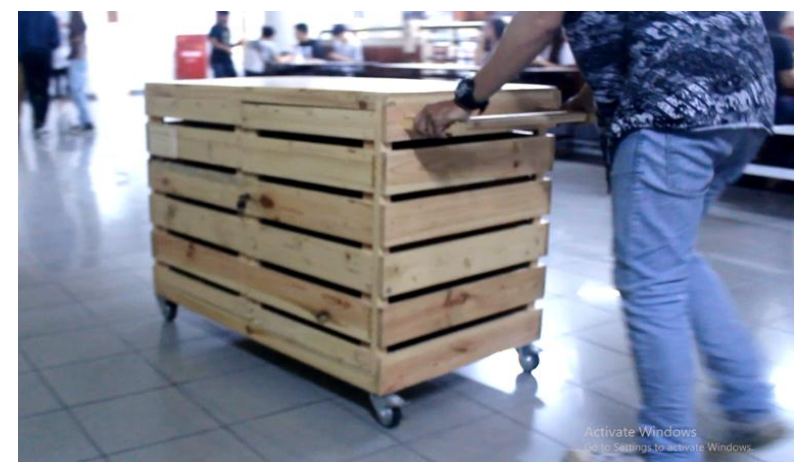

Gambar 10. Memindahkan gerobak

Dengan menggunakan gerobak, UKM bisa mendapatkan pendapatan yang stabil dan bisa mengembangkan bisnisnya hingga diketahui oleh banyak orang, terutama masyarakat Surabaya. Gerobak tersebut didesain sehingga memudahkan Ibu-Ibu UKM berjualan, dengan konsep MANTAP ( Mobility, Adaptable, Natural, Traditional, Assemble, Practical).
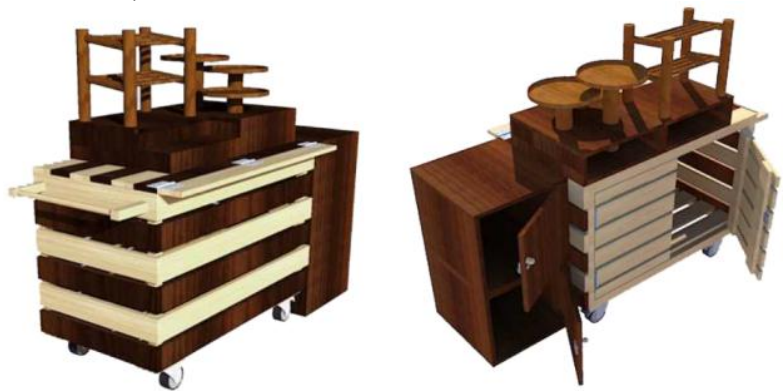

Gambar 11. 3D modelling gerobak

- Mobility, gerobak memiliki roda sehingga memudahkan untuk berpindah tempat pada saat berjualan.

- Adaptable, gerobak dapat beradaptasi dengan lokasi untuk berjualan, karena semua rak yang dapat diatur sesuai kebutuhan dan dapat dimasukkan kedalam gerobak sehingga ringkas dan efisien. 
- Natural, menggunakan material-material yang natural (kayu).

- Traditional, mengedepankan nilai tradisional, sehingga menggunakan tampah sebagai display kue untuk memunculkan nilai tradisional.

- Assemble, semua display kue dapat disusun sesuai kebutuhan dengan mudah.

- Practical, desainnya yang praktis sehingga memudahkan penjual.



Gambar 12. Gambar kerja gerobak

\section{Test}

Tahapan dimana melakukan uji coba dahulu terhadap prototype gerobak yang dihasilkan dengan menggunakannya untuk berjualan di wilayah kampus. Setelah digunakan untuk berjualan dan mendapatkan saran dari berbagai pihak (pembeli dan pihak UKM). Yang kemudian diserahkan kepada UKM Kampung Unggulan Kue untuk digunakan sebagai perabot untuk berjualan.

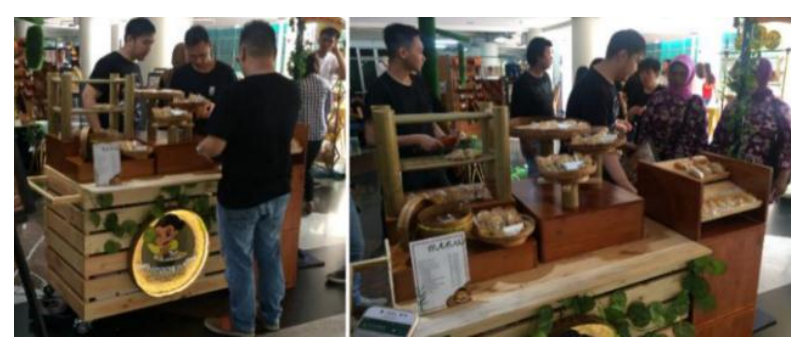

Gambar 13. Tahapan test

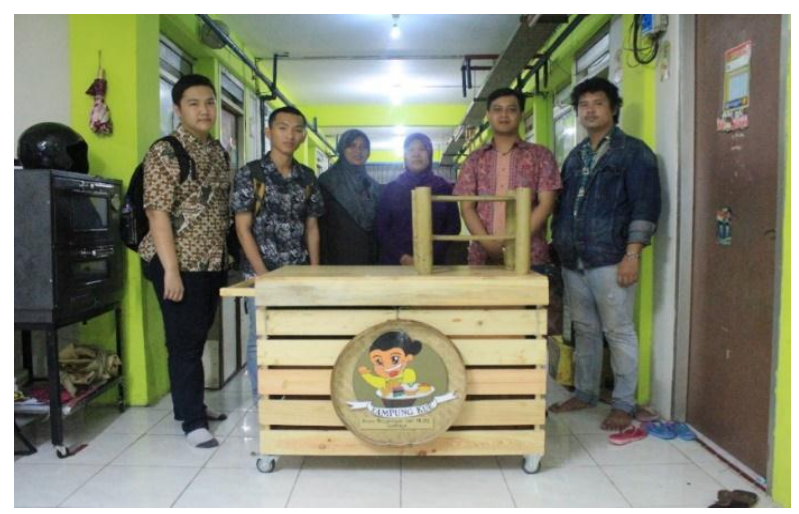

Gambar 14. Penyerahan gerobak kepada pihak UKM
Pada saat penyerahan, UKM memberikan ucapan terima kasih karena telah belajar bersamasama dari awal hingga akhir untuk menyelesaikan masalah yang ada dan atas gerobak yang telah didesain dan diproduksi untuk digunakan berjualan setiap harinya. Pihak UKM juga berharap bahwa gerobak yang telah dimilikinya dapat berguna untuk mengembangkan usaha yang dimiliki oleh mereka.

Setelah gerobak diserahkan, pihak UKM memanfaatkan gerobak dengan baik untuk berjualan kue-kuenya di pada sebuah acara.

Selama proses Service-Learning, ada beberapa hal yang menjadi pengalaman baru dari mahasiswa, dimana mahasiswa belajar untuk menyelesaikan masalah yang dimiliki oleh orang lain, sehingga mahasiswa harus bisa untuk memahami dan apa yang diperlukan dan dirasakan oleh UKM agar dapat memberikan solusi yang terbaik.

\section{KESIMPULAN}

Gerobak yang didesain untuk UKM Kampung Unggulan Kue dengan konsep MANTAP (Mobility, Adaptable, Natural, Traditional, Assemble, Practical), menjawab permasalahan yang terjadi di dalam UKM Kampung Unggulan Kue, yaitu UKM tidak memiliki outlet tetap dan perabot untuk berjualan sehari-hari, sehingga pendapatan yang diperoleh hanya bergantung pada pesanan. Dengan adanya gerobak, UKM dapat menggunakannya untuk berjualan di bazaar-bazaar, pasar malam, car free day, maupun pada saat berjualan sehari-hari dengan mudah. Dengan perabot yang lebih fleksibel ,UKM Kampung Unggulan Kue dapat meningkatkan penghasilan dan lebih dikenal oleh masyarakat, khususnya masyarakat Surabaya.

\section{REKOMENDASI}

Rekomendasi yang penulis berikan untuk beberapa pihak:

1. UKM Kampung Unggulan Kue dapat melakukan beberapa hal untuk dapat membantu perkembangan usaha yang dimiliki oleh mereka selain dengan berjualan dengan menggunakan gerobak, yaitu:

- Jaman sekarang ini adalah era digital, dimana semua aktivtitas dilakukan secara online, sehingga UKM bisa mencoba untuk berjualan secara online untuk dapat menjangkau pasar lebih luas sehingga mudah dikenal oleh masyarakat.

- Masyarakat dijaman sekarang ini lebih mementingkan penampilan dibandingkan dengan kualitasnya, sehingga UKM bisa melakukan inovasi untuk kue agar terlihat menarik dan baru. 
- Menggunakan packaging yang lebih menarik dan kreatif.

- Ikut serta dalam setiap event yang diadakan di Surabaya.

2. Rekomendasi untuk mahasiswa desain atau desainer lainnya, yaitu dapat mempergunakan ilmu yang dimilikinya untuk membantu UKM yang ada sehingga UKM dapat berkembang dengan lebih baik lagi dan membantu perekonomian masyarakat.

3. Untuk masyarakat, agar semakin peduli dengan UKM yang ada dengan membeli dan menggunakan produk yang dihasilkan oleh UKM Indonesia.

\section{UCAPAN TERIMA KASIH}

Penulis mengucapankan terima kasih yang sebesar-besarnya terhadap Ibu Anik Pudjiati beserta dengan seluruh anggota UKM Kampung Unggulan Kue atas partisipasi dan keterlibatannya dalam proses pembelajaran Service-Learning ini dan Ibu Diana Thamrin,S.Sn., M.T selaku pembimbing dalam mata kuliah Desain Produk Interior 3.

\section{DAFTAR PUSTAKA}

Ardiana, IDKR., Brahmayanti, L. A., \& Subaedi. (2010). Kompetensi SDM UKM dan pengaruhnya terhadap kinerja UKM di Surabaya. Jurnal Manajemen dan Kewirausahaan. Vol. 12.

Munasyita,S. (2017). Service Learning program sebagai salah satu metode untuk mewujudkan peran mahasiswa bagi masyarakat. laporan penelitian. Yogyakarta: Fakultas Ekonomika dan Bisnis Universitas Gajah Mada. Tidak Diterbitkan.

Nurhayati E, Mulyana, Ekowati V I and Meilawati. (2014). Inventarisasi makanan tradisional Jawa unsur sesaji di pasar-pasar tradisional kabupaten Bantula. Jurnal Penelitian Humaniora, Vol $19,124-140$

Agustin, L., Kusumarini, Y., Suprobo, F. P., Studi, P., Interior, D., Petra, U. K., \& Siwalankerto, J. (2014). Perancangan modular indoor booth untuk produk pakaian, sepatu dan makanan. Jurnal Intra, 2(2), 748-753. Retrieved from file://ID:/interior/Pra TA/Pra TA/Jurnal buat Pra TA/2274-4294-1-SM.pdf. 